\title{
Protection by culling: the crux of red deer management in National Parks
}

\author{
Dominika Cywicka, Magdalena Hędrzak, Mirosława Długosz \& Luiza Tymińska-Czabańska
}

Keywords: natural regulation, Cervus elsphus, hunting, protected area, artificial neural network

\section{Abstract}

Managing large ungulates in the territory of national parks requires comprehensive knowledge of many factors (population parameters, the distribution of animals and the number of their habitats, their feeding grounds, the intensity and direction of their migration), and skill in responding to the effects of negative chance events. A large number of the factors are by nature stochastic; thus, from a programming perspective, the issue of managing ungulate populations is difficult to formulate as an algorithm. This paper presents a model built using artificial neural networks (ANN). The results obtained with this model show that it is possible to maintain the population in a park without the necessity for culling within its boundaries. The study also demonstrated that culling specifically of hinds in these areas should be increased. The research presents alternative culling strategies for red deer populations in protected areas.
Profile

Protected area

Pieniny National Park

(NP), Gorce NP \& Ma-

gurski NP

Mountain range

Carpathians, Poland

\section{Introduction}

National Parks (NPs) came into existence primarily for the protection and preservation of nature: its geological features, flora and fauna. Game species such as red deer (Cervus elaphus), which often live within NPs, are also protected under the majority of Nature Protection Acts. A significant difficulty in maintaining the optimum size and structure for ungulate populations in European NPs and forest preserves is that, in the majority of cases, these protected areas are relatively small, and their topography and boundaries are less than optimal from the standpoint of maintaining a population of animals within the protected areas themselves. Thus with regard to deer (and their predators), the areas offered by the parks are markedly smaller than the actual ranges of the deer.

Difficulties in planning the protection of deer and in management are also associated with daily and seasonal migrations of animals (Harrison \& Bardgett 2004). The ungulate populations in NPs should be reduced by density-dependent mechanisms, in particular the pressure of predators, which causes a significant decrease in the number of herbivores per given area (Ripple $\&$ Beschta 2011). Like the deers' habitat, that of their predators can cover thousands of hectares of land (much of which may be well outside the boundaries of the protected areas). Thus the populations of red deer (and other large herbivores) and the predation effect spread beyond the area of parks themselves to neighbouring hunting districts. However, because the number of large predators is relatively small, it cannot be assumed that their presence will be sufficient to maintain appropriate levels for the herbivore populations.

Numerous authors point out that, for many reasons, hunting is not a good alternative to the presence of large predators (Ripple \& Beschta 2012).
Limiting the need to cull red deer within the boundaries of the NPs would reduce the effects on the deers' behaviour and comply with the ideological objectives which led to the parks' creation in the first place. However, reducing deer culling within the parks would also affect how deer are culled in the surrounding areas. This assumption was inspired by Simona Kossak (personal communication) and made in accordance with source-sink theory, a theory which is relevant for both planning and managing protected areas (Pulliam \& Danielson 1991) and their immediate surroundings. According to the source-sink theory, a well-managed $\mathrm{NP}$ or nature reserve should constitute a so-called source, in which births outnumber deaths, with some animals leaving when the population density approaches the limits of their habitat's capacity. In such a situation, the areas bordering on a nature reserve or NP should form a sink, where natural mortality and mortality due to hunting are higher than reproduction, and the population supports itself thanks to a continuous influx of animals from the source. This is possible if the density of a population in relation to the capacity of the habitat in the sink is clearly lower than it is in the source. Based on the source-sink theory, it ought to be possible to regulate the size of a population in a park by hunting in adjacent areas, which are inhabited by subpopulations. From a theoretical point of view, this model would help to reach a compromise between the interests of areas that border on the protected areas and are used for hunting on the one hand, and those of the Parks themselves.

Predictive advisory systems, which use techniques such as artificial neural networks (ANNs), can be helpful in making decisions that take into account the complexity of the issue. To an extent, ANNs imitate the basic operations of the neurons within the human brain. Through their specific structure, artificial neural 

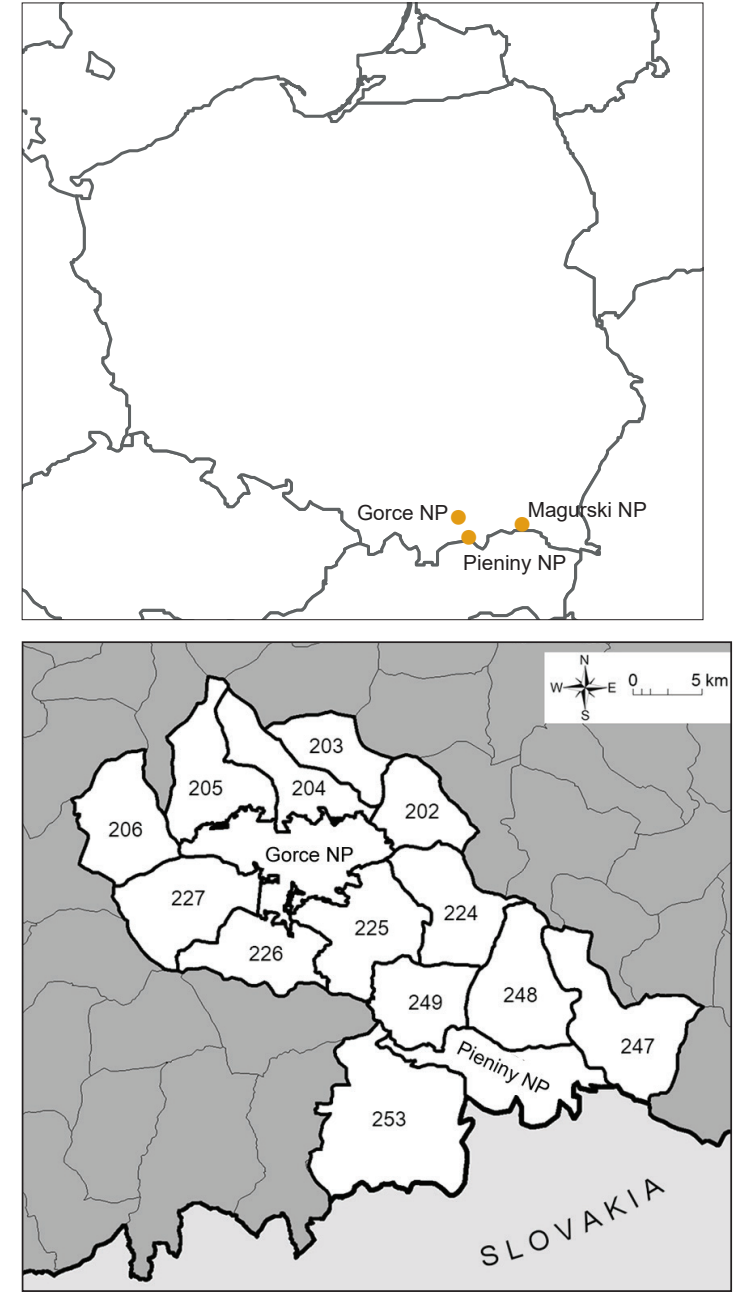

networks make it possible to copy non-linear relations, thereby finding a broad application in biology and ecology (Lek \& Guegan 1999). Many authors stress that modelling with the use of ANN gives better results than using other mathematical methods, including statistical ones (Őzzesmi \& Özesmi 1999). Because of the lack of full knowledge about certain phenomena and complex relations that frequently occur between individual components of biological systems, modelling using ANN in biological sciences seems more convenient than classic solutions. This degree of complexity and the lack of complete understanding mean that it is impossible to create a full and effective dynamic model which accurately reflects the functioning of a neural network in its entirety. ANNs turn out to be a good tool in such cases, because they make it possible to create models without the need to first formulate hypotheses; this also pertains to complex, multidimensional, non-linear models. Thanks to their ability to learn, the models do not require full a priori knowledge about the system being described.

Our research uses ANN to develop a theoretical model that takes into account the dynamics and size of deer populations in selected NPs and in areas where hunting is controlled, in order that culling in protected areas may be significantly limited or even

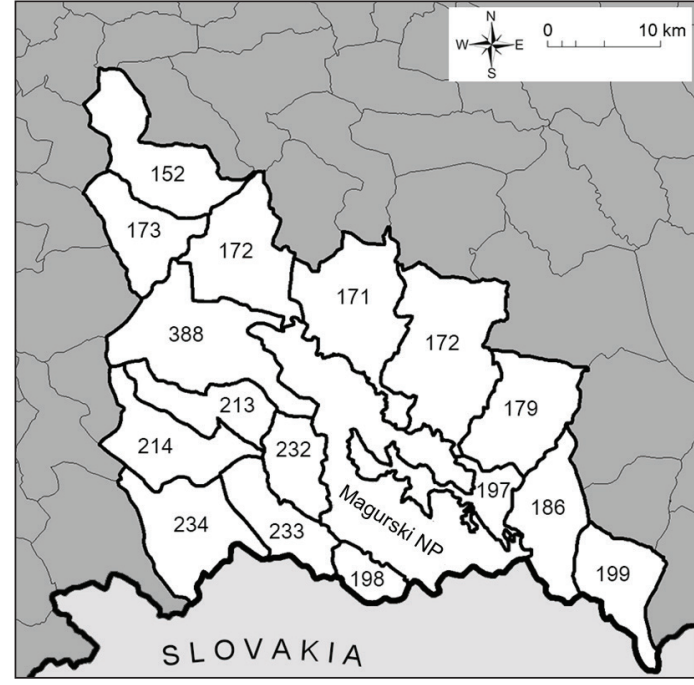

- locations of the National Parks (NP)

research area including

NPs and hunting districts

hunting districts not included in the model

national border

Figure 1 - Maps of the boundaries of Gorce National Park (NP), Pieniny NP, Magurski NP and the neighbouring bunting districts located in Southern Poland.

abandoned completely. The model also us to provide possible variants for managing and exploiting the deer that inhabit these areas.

\section{Materials and methods}

\section{Study area and data collection}

The sites in Southern Poland from which the data used for calculations originated were Pieniny National Park (PNP): 49 24'N; $20^{\circ} 27^{\prime}$ E; Gorce National Park (GNP): $49^{\circ} 33^{\prime} 30^{\prime \prime} \mathrm{N} ; 20^{\circ} 09^{\prime} 45^{\prime}$ E, and Magurski National Park (MNP): $49^{\circ} 30^{\prime} \mathrm{N} ; 2^{\circ} 30^{\prime} \mathrm{E}$, together with the neighbouring areas where hunting is controlled (Figure 1).

\section{ANN modelling}

There are many types of ANN, but the most frequently used and simplest type is a multi-layer feedforward perceptron (MLP) (Agatonivic-Kustrin \& Beresford 2000). A typical network contains so-called nodes or neurons, which are interconnected and weighted with elements of weight matrix (W) (Figure 2). The sum of the weighted inputs $(x 1, x 2, x 3, \ldots, x n)$ is transformed by a transfer function $f(a)$, which is usually nonlinear: $\mathrm{a}=\mathrm{f}\left(\mathrm{W}_{\mathrm{x}}+\mathrm{b}\right)$ (Hagan et al. 1996), (b is the bias). 


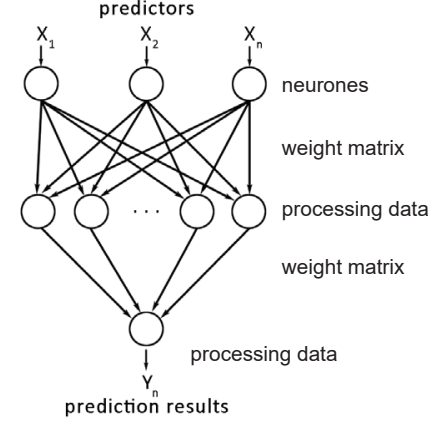

Figure 2 - Three-layer artificial neural network architecture.

Usually, an MLP model consists of three layers: input layer (containing explanatory variables), hidden layers (usually 1 or 2 are sufficient), and output layer (which gives prediction results) (Özesmi \& Özesmi 1999).

For this study, an MLP-type network was adopted to predict the numbers of red deer within three $\mathrm{Na}$ tional Parks, with 1 output layer, 1 hidden layer (5 hidden neurons), and back-propagation (Rumelhart et al. 1986), the back-propagation being based on the Levengerg-Marquardt algorithm for training. The input and hidden layers used a hyperbolic tangent for the activation of neurons; in the output layer, the activation function was a linear one.

The model's input included information about mortality (the sum of culled deer and natural mortality) for stags, hinds and calves as separate groups, and about the locations where culling took place (or where a dead animal was registered). The data for the number of deer obtained during monitoring in national parks was used for the network output.

For GNP, data were collected for the years 19972008; for MNP, for the years 1995-2007; and for PNP, for the years 1998-2008. The data from the areas adjacent to the parks covered the same periods and concerned deer mortality in controlled hunting districts (i. e. areas of not less than 3000 hectares, where hunting is managed independently of the NPs).

Data were obtained from Hunter Breeding Plans (Kraków Region and Krosno Polish Hunting Association) and, in the case of the State Forests' Game Breeding Centres (No. 253), from the Krościenko Forest District. Information about physiographic and natural conditions was obtained courtesy of the Regional Directorate of National Forests in Kraków and Krosno (current Master Development Plans for individual Forest Districts).

General operating diagram of a neural network model

The modeling was carried out in three stages (Figure 3). The first stage comprised all elements of the construction of the model (data pre-processing, an analysis of sensitivity, and carrying out tests for generalization). In the second stage, the number of animals shot in an NP was reduced and the reaction of the model was observed. This was one of the elements of the analysis of the correctness of the model's operation (at this stage it was expected that the number of animals in the NPs would increase - see Figure 3: $\mathrm{C}_{\mathrm{t}+1}>\mathrm{B}_{\mathrm{t}+1}$ in dashed ellipse). Constructed in this way, the model allowed us to check how the deer population in a park would change when deer mortality in the hunting districts increased. In the final stage, the number of animals culled in controlled hunting districts surrounding the NPs was increased. (More specifically, the numbers of hinds culled was increased, because the analysis of sensitivity and practical guidelines indicated that culling would be most effective if this group was the object of the culling). The expected result of the third stage of the modeling was a reduction in the numbers of animals in the NPs compared to the number recorded there in specific years, which were considered the target sizes for the populations (see Figure 3: $\mathrm{C}_{\mathrm{t}+1} \approx \mathrm{B}_{\mathrm{t}+1}$ ).

\section{Stage 1}

$A_{t}=a_{t}+a_{t}$

A ... total mortality of deer (stags, hinds and calves) in NP [at time $\mathrm{t}$ ]

$a_{t} \ldots$ natural mortality [at time $t$,

$a_{t} \ldots$ reduction through hunting [at time $\left.t\right]$.

$\mathrm{B}_{\mathrm{t}+1} \ldots$ total number of deer in NP (monitoring) [at time $\mathrm{t}+1]$

\section{Stage 2}

$\mathrm{C}_{\mathrm{t}+1}$... estimated total number of deer in NP: prognosis [at time $\mathrm{t}+1]$

\section{Stage 3}

$D_{t}=d_{t}+d_{t}^{\prime}+d^{\prime \prime}$

$\mathrm{D}_{\mathrm{t}}$... total deer mortality (natural and selective hunting) in controlled hunting districts surrounding NP [at time $\mathrm{t}]$

$\mathrm{d}_{\mathrm{t}}$... stag mortality,

$\mathrm{d}_{\mathrm{t}}, \ldots$ hind mortality,

$d{ }_{t} \ldots$ calf mortality.

\section{Model fitting and testing}

Assessing the accuracy of the prognosis included, first of all, running tests on the network's ability to generalize. The tests were conducted in two ways: (1) a dataset was divided into two subsets - teaching and testing, in the proportion of 1:1 - to obtain a longterm prognosis; (2) division of the dataset into several subsets on which learning was conducted; the number of animals in the following years was then predicted (1 time-step ahead), giving a short-term prognosis. The prognoses were verified using universal quality metrics of the prognoses of time series (Rongxia \& Weiskittel 2010): 


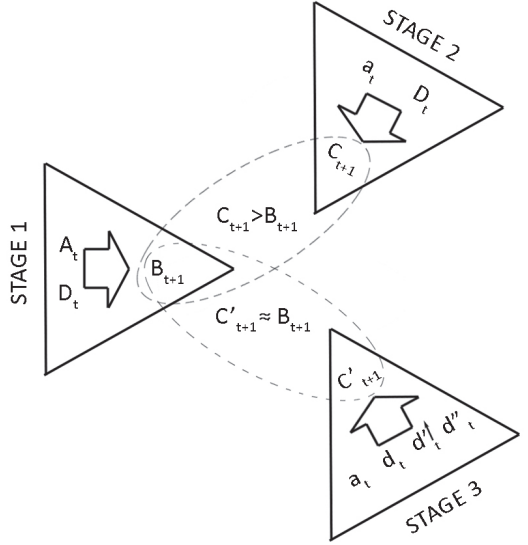

Figure 3 - The operation of the neural model. $\left(A_{t}\right)$ total mortality of deer. (a) natural mortality [at time $t],\left(a_{t}^{\prime}\right)$ reduction through bunting [at time $t],\left(B_{t+1}\right)$ total number of deer in NP (monitoring) [at time $t+1],\left(C_{t+1}\right)$ estimated total number of deer in NP: prognosis [at time $t+1],\left(D_{t}\right)$ total deer mortality (natural and selective bunting) in controlled bunting districts surrounding NP [at time t], $\left(d_{t}\right)$ stag mortality, $\left(d_{t}^{\prime}\right)$ bind mortality, $\left(d_{t}\right.$ ") calf mortality. Dashed ellipse: information about expected relation between outputs of presented stages.

Root mean squared error (RMSE):

RMSE $=\sqrt{\frac{\sum\left(y_{t}-y_{t}^{\prime}\right)^{2}}{n}}$

Model efficiency (EF):

$E F=1-\frac{\sum\left(y_{t}-y_{t}^{\prime}\right)^{2}}{\sum\left(y_{t}^{\prime}-\bar{y}_{t}^{\prime}\right)^{2}}$

Mean absolute percent error (MAPE):

MAPE $=\frac{100 \%}{n} \sum \frac{\left|y_{t}-y_{t}^{\prime}\right|}{y_{t}}$

U Theil (U):

$U=\sqrt{\frac{\sum_{\substack{(n-1) \\(n-1)}}\left(\frac{y_{t+1}^{\prime}-y_{t+1}}{y_{t}}\right)^{2}}{\sum_{(t=1)}^{(n-1)}\left(\frac{y_{t+1}-y_{t}}{y_{t}}\right)^{2}}}$

Directional symmetry (DS):

$D S=100 \frac{\sum_{t=1}^{n} d_{t}}{n}, d_{t}=\left\{\begin{array}{l}1,\left(y_{t}-y_{t-1}\right)\left(y_{t}^{\prime}-y_{t-1}^{\prime}\right)>0 \\ 0, \text { otherwise }\end{array}\right.$

$y_{t} \ldots$ observed value for time $\mathrm{t}$

$y_{t}^{\prime} \ldots$ predicted value for time $\mathrm{t}$

On the basis of the universal metrics, for MNP and PNP the model estimated long-term prognoses (I) better than short-term prognoses (II), as shown in the lower burden of the prognoses and their greater precision (Table 1). The MAPE value demonstrates that for MNP, over the period of the prognosis, the error occurred in approximately $1.66 \%$ of the prognosis value. For GNP, the forecast bias was lower for
Table 1 - Measurements of quality for Gorce National Park (GNP), Pieniny NP (PNP), Magurski NP (MNP) for a long-term prognosis (I) and a short-term prognosis (II).

\begin{tabular}{|l|r|r|r|r|r|r|}
\cline { 2 - 8 } \multicolumn{1}{c|}{} & \multicolumn{3}{l|}{ MNP } & \multicolumn{1}{l|}{ GNP } & \multicolumn{2}{l|}{ PNP } \\
\cline { 2 - 8 } \multicolumn{1}{c|}{} & \multicolumn{1}{l|}{ II } & \multicolumn{1}{l|}{ I } & \multicolumn{1}{l|}{ II } & \multicolumn{1}{l|}{} & \multicolumn{1}{l|}{ I } \\
\hline RMSE & 35.05 & 89.74 & 29.06 & 8.8 & 0.04 & 0.89 \\
\hline MAPE & 1.66 & 15.82 & 1.17 & 2.44 & 0.61 & 7.03 \\
\hline U Theil & 0.49 & 2.16 & 1.04 & 0.74 & 0.99 & 1.71 \\
\hline DS [\%] & 83.3 & 44.4 & 33.3 & 87.5 & 80 & 57 \\
\hline
\end{tabular}

the short-term prognosis (II). During the testing period, fewer errors were made for prognosis II than for prognosis I, which constitutes about $2.44 \%$ of the forecast value - thus, more than in the case of prognosis I (1.17\%). For PNP, the forecast bias was lower for long-term prognosis $(0.61 \%)$. On the basis of the $U$ value, we can state that the model is suitable for forecasting values for MNP and PNP many years ahead, and one time-step ahead for GNP. The $U$ value for PNP is close to 1, which points to the conclusion that although the forecasts of the model are better than the naïve forecast, they are still closer to the real values of the preceding period.

The value of the DS coefficient confirms that for parks MNP and PNP the model turned out markedly better in the long-term forecast, contrary to the case for GNP.

\section{Results}

The sensitivity analysis of the model provides important information about the input variables that were introduced into the model. Thanks to the analysis, one can reject the variables which have a negligible impact on the end result, and distinguish the variables that determine it the most (Lek et al. 1999). The results of the sensitivity analysis provided information about the distribution of further hinds culled in hunting districts surrounding the NPs. As a result of such calculation analyses revealed:

- 6 variants for MNP,

- 6 variants for GNP,

- 12 variants for PNP.

Adopting the sum of additional culled hinds as $100 \%$ within each variant (Figure 4), the percentage of additional culled hinds in every hunting district surrounding individual parks was calculated.

The culling of hinds in the districts located south of GNP (districts No. 227, 226, 225) could be increased significantly and proportionately to other districts. Although in district 224 (situated southeast of the park) the proposed increase in the controlled hunting of hinds is low, it still appears in each of the proposed variants. This could demonstrate that this hunting district plays a significant role in maintaining the number of deer living in the park. The monitoring conducted by the park's employees showed that dur- 


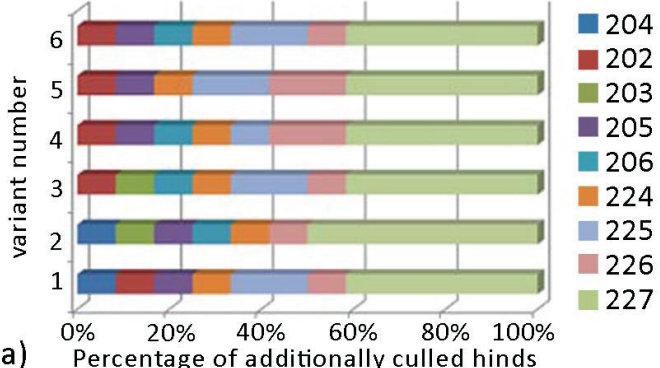

a) Percentage of additionally culled hinds

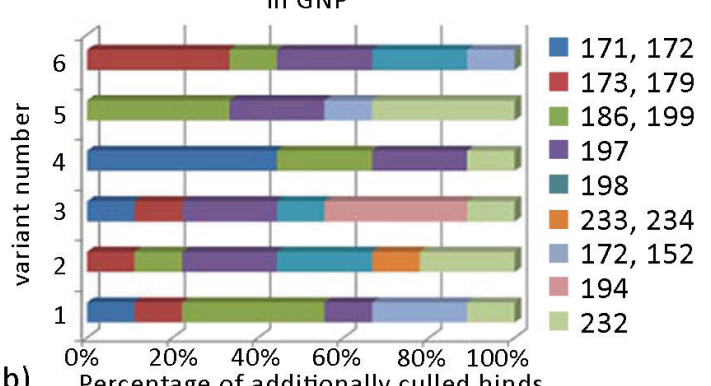

b) Percentage of additionally culled hinds in MNP

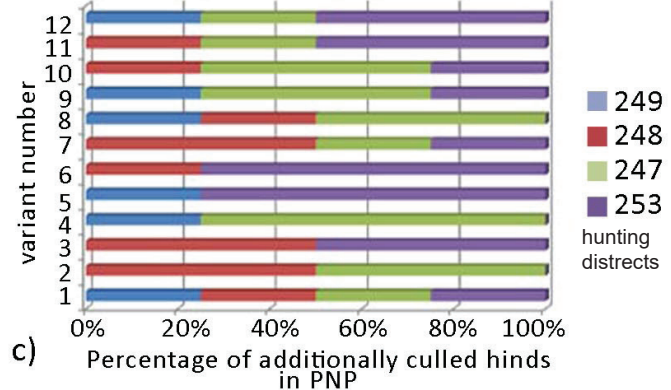

Figure 4 - Percentage shares of additional culls in surrounding bunting districts see Figure 1 for the location of the districts. (a) GNP for each of the 6 variants; (b) MNP for each of the 6 variants; (c) PNP for each of the 12 variants.

ing the winter months the deer moved to the southern parts of the park for food. Significant damage to the stand of young fir trees has been noted in this area, the result of increased animal numbers and feeding.

The southern part of the park constitutes a crossroads of migration paths to the south and from west to east. This creates a real possibility for the limited hunting of hinds in those districts south of the GNP that are identified by the ANN model.

Particular attention should be drawn to district No. 197 in MNP, where the results obtained from the ANN model show increased hunting for each variant. This probably results from geographic and natural conditions. From a nature-protection standpoint, district No. 197 should be included in the protection zone for the park's wild game.

The results generated by the ANN model for PNP show that culling in districts No. 253 and 247 would account for the greatest number of additional culled hinds. We can conclude from the results that a small increase of hind culling in the districts surrounding PNP would be sufficient to keep the deer population in this territory at an appropriate level.

\section{Discussion and conclusions}

European red deer (Cervus elaphus) inhabit the majority of NPs in Europe. Regulating the population of this species by culling in protected areas diverges from common conceptions of how NPs function and thus stirs a lot of controversy. However, it is the most popular method of limiting the deer population. Research conducted in sixteen European parks by Heurich (2012) showed that in only one of them culling was not being carried out. In the others, the deer are both being culled and fed. Another solution to the ungulates issue in NPs is a periodic enclosure of the animals in fencedin areas within which culling (Gerner et al. 2012) or fertility control (Bradford \& Hobbs 2008) take place.

The results obtained indicate that the number of animals in a given area can be regulated by managing the adjoining areas. This is in line with the research of other authors (Perzanowski \& Krzakiewicz 2000; Clutton-Brock at al. 2002; Lubow et al. 2002; FuentesAllende 2015). Various authors also indicate that the dynamics of stags are influenced more by the density of hinds than by the density of mixed-sex groups (Clutton-Brock 1982; Fuentes-Allende 2015). Under favourable environmental conditions, more females than males are born. The dynamics of change in freeroaming animal populations depends on the age and sex structure of the herd, prolificacy of the species, and mortality. The number of offspring depends on the number of females that are able to reproduce. There is therefore an indirect relationship between the number of females and simple, broadened or narrowed natural and/or regulated mortality. Not without significance is the fact that the home range of females is significantly smaller than that of males (Kamler et al. 2004). Against the above, a stronger relationship can be expected between the mortality of hinds and the mortality of the population as a whole researched in a given territory.

The results of estimations confirmed a strong correlation between the culling of hinds in the areas surrounding a NP and the size of the park's population. Our analyses also determined the additional number of hinds to be culled in hunting grounds. The results provided us with information about the size of the increase in culling which would ensure that the number of animals in the park did not exceed the number of individual animals indicated over the years. The results of the analyses seem to justify the conclusion that regulating the number of females in adjacent areas where populations are increasing plays a significant role. Similar results were presented by Lubow et al. (2002). On the basis of an analysis of data from parts of the Rocky Mountain National Park and its adjacent areas, Lubow et al. developed a dynamic model that reflects changes in the numbers of the sub-population of deer inhabiting the adjacent areas. The results obtained from the model demonstrated the necessity of culling a greater number of hinds in the areas contiguous to 
Rocky Mountain NP in order to lower the number of deer within the park itself.

The effectiveness of this approach is confirmed not only by model tests but also by practical tests conducted in various regions of the world. Perzanowski and Krzakiewicz (2000) found that the hinds that had left the higher parts of the Bieszczady mountains (Bieszczady NP, Poland) for the winter were not returning to their summer ranges in spring because of the huge reduction in their numbers while they were in their wintering grounds. The total number of deer within the NP therefore decreased. This reduction was so significant for the entire area that the authors flagged the need to coordinate activities among several regions all managing the red deer population in this part of Poland.

Based on experiments that they carried out on the Isle of Rhum (Scottish Hebrides), Clutton-Brock et al. (2002) stated that limiting the density of one sex by culling should bring about specific effects for the local subpopulation of deer. According to the authors, after a drastic $50 \%$ drop in the density of females in comparison to the initial level, in the area where hinds were culled the number of resident stags increased by as much as $25 \%$, despite there being no changes in the management rules. Such an increase in the number of stags can be a motivating factor for hunters in the areas surrounding the NPs who are implementing management activities based on the shooting of stags.

Clutton-Brock et al. (2002) found yet another effect in cases where harvesting the stags was done intensively, while the density of the hinds stayed the same. After a few years of intensive stag-culling in the experimental area, the number of stags in the neighbouring areas also dropped (by 50\%). Meanwhile, the number of hinds in the area where the culling of males was taking place showed an increase of over $50 \%$.

Fuentes-Allende (2015) analysed changes on the Isle of Rhum, in a territory where for forty years there was no deer harvesting, and in the areas adjacent to the territory. He found that in the area excluded from the harvesting, the total number of males decreased, the survival and the share of old stags in the population increased, and the number of hinds increased slightly. The author expressly recommended a change in the harvesting strategy in the adjacent areas to limit the emigration of the stags, because the sheer numbers emigrating threatened to cause the extinction of the deer population in the protected area. Furthermore, he found that the hinds and the stags responded differently when the population density was reduced by culling. Intensive hunting can cause the stags to leave a population, while the hinds increase in number.

This behavioural strategy of the deer confirms the lack of justification for their culling within the NPs under discussion. Fuentes-Allende (2015) also found that in the area where no hunting was taking place, the lack of large predators was problematic, because the deer, especially hinds, did not migrate to adjacent areas. This issue does not pertain to the NPs discussed in this study, however, because they are populated by both wolves (Canis lupus) and lynxes (Lynx lynx).

The simultaneous intensive harvesting of hinds in the areas neighbouring NPs and a discontinuation of culling in the protected areas can, in the initial period of implementing the strategy, cause an outflow of deer from the park; there is a negative correlation between the emigration of the stags and deer density (Loe et al. 2009). In particular, young, two-year-old stags leave their place of birth and settle in areas with a less dense deer population.

When comparing the models for managing the deer populations in the three NPs discussed here, the results for the Magurski NP seem most significant. Ever since the park was established (1995), the level of deer harvesting within the park's boundaries has been higher than for any other Polish NP. It should also be noted that culling was intensified in this park in the year the park was established, and it continued for many years at a higher level than before the park's creation (Hędrzak 2018). According to Wajdzik et al. (2017), the population density of the ungulates in the park threatens biodiversity, and the large number of predators is not sufficient to limit the increase in deer numbers. The authors found that the deer migrating from the park could cause damage in a commercial forest as far away as $100 \mathrm{~km}$ from its borders, and assumed that the deer would move along the green corridors through the forests in hunting districts 233 and 234. Our models for MNP show that reducing the number of deer in these hunting districts has no significance for regulating the numbers of deer in the park. However, since the increase in damage in the Gorlice and Losie Forestry Districts mentioned by Wajdzik et al. (2017) arises from the high density of deer in Magurski NP, limiting the damage could be achieved by increasing the culling of hinds in the districts situated east of the park, especially in district No. 197, which cuts into the area being protected (see map in Figure 1).

The results indicate that it is possible to maintain deer numbers in protected areas by appropriate management of the deer population in adjacent areas, where game management is realized. Practical recommendations pertain primarily to increasing the culling of hinds in order to correct the herds' sex structure which, according to the national parks' services and practitioners, is distorted in areas neighbouring the NPs. The results also show that in the future, after appropriate modification, it will be possible to implement the model in supporting the deer-management strategies of further protected areas.

\section{References}

Agatonivic-Kustrin, S. \& R. Beresford 2000. Basic concepts of artificial neural Network (ANN) modeling and its application in pharmaceutical research. Journal of Pharmaceutical and Biomedical Analysis 22: 717-727. 
Bradford, J.B. \& N.T. Hobbs 2008. Regulating overabundant ungulate populations, An example for elk in Rocky Mountain National Park, Colorado. Journal of Environmental Management 86: 520-528.

Clutton-Brock, T.H., T.N. Coulson, E.J. MilnerGulland, D. Thomson \& H.M. Armstrong 2002. Sex differences in emigration and mortality affect optima management of deer population. Nature 415: 633-637.

Clutton-Brock, T.H., F.E. Guinness. \& S.D. Albon (eds.) 1982. Red deer: behavior and ecology of two sexes.

Fuentes-Allende, N. 2015. Hunting in neighbouring areas influences the dynamics of an unmanaged population of red deer. MSc Thesis, Imperial College London: 1-28.

Gerner, J., A. Selter, M. Heurich, S. Günther \& U. Schraml 2012. How Attitudes are Shaped: Controversies Surrounding Red Deer Management in a National Park. Human Dimensions of Wildlife: An International Journal 17(6): 404-417.

Harrison, K.A. \& R.D. Bardgett 2004. Browsing by red deer negatively impacts on soil nitrogen availability in regenerating native forest. Soil Biology \& Biochemistry 36: 115-126.

Hędrzak, M. 2018. The models of management of red deer (Cervus elaphus L.) population in South-Eastern Poland - consequences and predictions. Kraków. [In Polish with English summary]

Heurich, M. 2012. Assessment of the naturalness of the red deer management in Central European national parks. Allgemeine Forst und Jagdzeitung 184(1/2): 1-16. [In German with English summary]

Kamler, J.F., B. Jędrzejewska \& S. Miścicki 2004. Red deer - a tale of two deer. In: Jedrzejewska, B. \& J.M. Wojcik (eds.), Essays on Mammals of Biatowieża Forest: $51-58$.

Lek, S. \& J.F. Guegan 1999. Artificial neural Network as tool in ecological modelling an introduction. Ecological Modelling 120: 65-73.

Loe, L.E., A. Mysterud, V. Veiberg \& R. Langvatn 2009. Negative density-dependent emigration of males in an increasing red deer population. Proceedings of the Royal Society of London. Series B, Biological sciences Royal Society 276: 2581-2587.

Lubow, B.C., F.J. Singer, T.L. Johnson \& D.C. Bowden 2002 Dynamics of interacting elk populations within and adjacent to Rocky Mountain National Park. Journal of Wildlife Management 66: 757-775.

Özesmi, S.L. \& U. Özesmi 1999. An artificial neural network approach to spatial habitat modelling with interspecific interaction. Ecological Modelling 116: 15-31.

Perzanowski, K. \& H. Krzakiewicz 2000. Population of the red deer in the Bieszczady Mountains. In: Głowaciński, Z. (ed.), Biesqczady Monographs IX: Vertebrates of the western Bieszczady with special reference to the Bieszcrady National Park: 179-191. [In Polish with English summary]

Pulliam, H.R. \& B.J. Danielson 1991. Sources, sinks, and habitat selection, a landscape perspective on population dynamics. American Nature 137: 50-66.
Ripple, W.J. \& R.L. Beschta 2011. Tropic cascades in Yellowstone. The first 15 years after wolf reintroduction. Biological Conservation 145: 205-213.

Ripple, W.J. \& R.L. Beschta 2012. Large Predators Limit Herbivore Densities in Northern Forest Ecosystems. European Journal of Wildlife Research 58: 733.

Rongxia, L. \& A.R. Weiskittel 2010 Comparison of model forms for estimating stem taper and volume in the primary conifer species of the North American Acadian Region. Annales of Forest Science 67: 302.

Rumelhart, D.E., G.E. Hinton \& R.J. Williams 1986. Learning representations by back-propagation error. Nature 323: 533-536.

Wajdzik, M., Z. Kołodziej, P. Bilański \& K. Szyjka 2017. Forest management and hunting in areas adjacent to national parks: the example of the Magura $\mathrm{Na}$ tional Park. Forest Research Papers 78(2): 129-135.

\section{Authors}

\section{Dominika Cywicka' - corresponding author}

is a researcher and lecturer at the University of Agriculture in Krakow (Poland), specializing in data analyses in the management of natural resources and forestry, especially using artificial intelligence techniques. E-mail: d.cywicka@urk.edu.pl

Magdalena Hędrzak - corresponding co-author specializes in the protection and management of wildlife, especially game species. She also works for the „Other World“ Foundation and as a guide in the Ojcowski National Park (Poland). „Other World“ Foundation, Dobrynin 266, 39-322 Dobrynin, Poland. E-mail: hedrzakmagdalena@gmail.com

\section{Mirosława Długosz}

is a researcher and lecturer at the AGH University of Science and Technology, Krakow, involved notably in data analysis and the development of physiotherapy support techniques. She was a laureate of the Top 500 Innovators Program at Stanford University (2012), and is the originator, co-founder and president of the Board of the Creativity and Innovation Lab Foundation. AGH University of Science and Technology, Faculty of Electrical Engineering, Automatics, Computer Science and Biomedical Engineering. E-mail: mmd@agh.edu.pl

\section{Luiza Tymińska-Czabańska}

is a $\mathrm{PhD}$ candidate in the Department of Biometry and Forest Productivity, University of Agriculture, Krakow (Poland). She specializes in the impact of climate change on the growth dynamics of tree stands and forest productivity.

${ }^{1}$ University of Agriculture, Krakow Faculty of Forestry Department of Biometry and Forest Productivity. 